\title{
Training and administration of epinephrine auto-injectors for anaphylaxis treatment in US schools: results from the EpiPen4Schools ${ }^{\circledR}$ pilot survey
}

\author{
This article was published in the following Dove Press journal: \\ Journal of Asthma and Allergy \\ 17 June 2016 \\ Number of times this article has been viewed
}

\author{
Susan L Hogue' \\ Diana Goss' \\ Kelly Hollis' \\ Suyapa Silvia ${ }^{2}$ \\ Martha VWhite ${ }^{3}$ \\ 'Health Solutions, RTI International, \\ Research Triangle Park, NC, \\ ${ }^{2}$ Education and Workforce \\ Development, RTI International, \\ Research Triangle Park, NC, ${ }^{3}$ Institute \\ for Asthma and Allergy, Wheaton, MD, \\ USA
}

Background: Anaphylaxis is a serious, potentially life-threatening condition. Adequate preparation for anaphylaxis management is imperative for school personnel. This descriptive pilot study assessed preparedness of US schools to manage anaphylactic reactions.

Methods: An exploratory, cross-sectional, web-based, pilot survey assessed the occurrence and characteristics of anaphylactic events, as well as training provided to school personnel for the recognition and treatment of anaphylaxis. Eligible US schools were participants in the EpiPen4Schools ${ }^{\circledR}$ program during the 2013-2014 school year. EpiPen4Schools provides EpiPen ${ }^{\circledR}$ (epinephrine injection) Auto-Injectors and training materials to qualifying US schools. Survey data were parsed by US Census Bureau region and state and were evaluated using descriptive statistics.

Results: Schools from all 50 states and the District of Columbia participated in the survey $(\mathrm{N}=6,019)$. Among schools that provided information on anaphylactic events, $11 \%(607 / 5,683)$ reported the occurrence of one or more events, with significant variability in incidence across census regions and among states. A total of 5,613 schools provided information regarding which staff members were trained to recognize the signs and symptoms of anaphylaxis. Thirty-six percent of schools $(2,022 / 5,613)$ indicated that only the school nurse and select staff were trained in anaphylaxis recognition. The proportion of schools in which most or all school staff received such training differed by region/state (range, 13\%-100\%). A total of 5,578 schools provided information on which staff were permitted to administer epinephrine. The majority of schools $(54 \% ; 3,024 / 5,578)$ permitted only the school nurse and select staff to administer epinephrine, although percentages varied by region/state (range, 4\%-100\%).

Conclusion: Schools differed substantially in their preparedness to manage anaphylaxis, with significant disparities in staff training and permission to treat. Given the ramifications of delayed treatment, removing barriers to the recognition and treatment of anaphylactic events in schools is an important public health goal.

Keywords: anaphylaxis, epinephrine, epinephrine auto-injector, preparedness, school nurse, school staff training

\section{Background}

The prevention and management of anaphylaxis in the school setting is increasingly recognized as a public health concern as the incidence of food allergies, a major trigger for anaphylaxis, appears to be on the rise in children. ${ }^{1}$ From 1997 to 2007, the prevalence of reported food allergy in the US increased by $18 \%$ in children $<18$ years of age. ${ }^{2}$
RTI Health Solutions, 200 Park Offices

Drive, Research Triangle Park, NC

27709, USA

$\mathrm{Tel}+191954 \mid 6213$

Fax + I 91954I I275

Email shogue@rti.org 
Unfortunately, many times the school is unaware that a child has a life-threatening allergy before the occurrence of an anaphylactic event. ${ }^{3}$ Likewise, it is not uncommon for a child to experience a first-time anaphylactic attack in the school setting. ${ }^{4}$

Often, children who experience an anaphylactic reaction do not receive epinephrine, the first-line treatment option, before presentation to the emergency department. ${ }^{5,6}$ Delay in the recognition and treatment of anaphylaxis has serious ramifications from hospitalization ${ }^{5}$ and biphasic reactions ${ }^{7}$ (ie, a reoccurrence of anaphylaxis symptoms hours after the index event) to death. ${ }^{8,9}$ Indeed, a majority of fatalities due to anaphylaxis that have been observed among adolescents and young adults have involved a lack of timely access to epinephrine. ${ }^{9}$ Hospitalization also has serious repercussions as it is disruptive to school attendance and daily activities and is a source of financial burden. In the US, hospitalizations for anaphylaxis are estimated to cost $\$ 4,500$ per event, ${ }^{10}$ and anaphylaxis is estimated to have total direct expenditures ranging from $\$ 288$ million to $\$ 3.7$ billion. ${ }^{11}$ To prevent or mitigate these adverse sequelae, adequate training programs are needed to properly educate school personnel to recognize and treat anaphylactic reactions.

The results presented here from a pilot survey among US schools participating in the EpiPen4Schools ${ }^{\circledR}$ program (Mylan Specialty L.P., Canonsburg, PA, USA) describe the occurrence of anaphylactic reactions and the training and personnel resources available to manage these events. Evaluating these aspects of anaphylaxis management will allow for a better assessment of school preparedness to deal with these serious and potentially life-threatening events.

\section{Methods}

\section{Data source}

Eligible schools were participants in the EpiPen4Schools program, which provides EpiPen ${ }^{\circledR}$ (epinephrine injection) Auto-Injectors (Mylan Specialty L.P.) and training materials to qualifying public and private kindergarten, elementary, middle, and high schools in the US. Participating schools received two EpiPen Auto-Injector 2-packs, two EpiPen $\mathrm{Jr}^{\circledR}$ Auto-Injector 2-packs, or one of each 2-pack free of charge. Of the $>40,000$ schools enrolled in the program, 32,387 schools had available contact information and were invited to participate in the survey.

The 15-question, web-based survey was to be completed by the person best qualified to provide information on anaphylactic events and preparedness, which was most often the school nurse. ${ }^{12}$ Responses were limited to events that occurred during the 2013-2014 academic school year. A total of 6,019 surveys were received between May 21, 2014 and July 9, 2014. Study design and survey methodology have been previously described in greater detail. ${ }^{12}$

\section{Data analysis}

Descriptive statistics were used to report the characteristics of participating schools (eg, census region, state), anaphylactic events, and staff training. Statistics were unweighted and, therefore, did not account for potential variation in individual school populations. Most questions included a count of missing data, as respondents were not required to answer every question. Therefore, percentages calculated for the descriptive statistics were derived using the total number of responses per question.

\section{Ethics}

The study was submitted to the RTI institutional review board (IRB) for approval, which determined that the research activity did not constitute research involving human subjects as defined by the US Code of Federal Regulations (45 CFR 46.102). The approval of these activities by the RTI IRB was not necessary; therefore, an exemption was granted.

\section{Results \\ Respondents}

The number of schools that enrolled in the EpiPen4Schools program varied by region and state, with the largest number of participating schools in the Northeast and the greatest singlestate participation rate in New York (Table 1). Individual state survey participation rates ranged from $1 \%$ to $52 \%$. There was no apparent association between the number of schools within a state that enrolled in the EpiPen4Schools program and percentage of schools that responded to the survey. However, survey participation rates were the lowest among the largest school districts and, in some cases, large districts were unable to participate at all because of requirements for research approval that could not be completed within the time frame for the study.

\section{Anaphylactic events}

Of the 6,019 schools that participated in the survey, 5,683 provided information on the occurrence of anaphylactic events, with $607(11 \%)$ reporting that one or more anaphylactic events occurred during the 2013-2014 school year. A total of 919 events were described. ${ }^{12}$ On a state-by-state basis, the number of anaphylactic events ranged from no events to a high of 103 events. When calculating the mean number of anaphylactic events per school (ie, number of anaphylactic events in a given 
Table I School participation by region and state

\begin{tabular}{|c|c|c|c|c|c|}
\hline State & Schools invited, $n$ & $\begin{array}{l}\text { Schools } \\
\text { participated, n (\%) }\end{array}$ & State & Schools invited, n & $\begin{array}{l}\text { Schools } \\
\text { participated, n (\%) }\end{array}$ \\
\hline Northeast & & & Midwest & & \\
\hline Connecticut & 893 & $179(20)$ & Illinois & 2,282 & $312(14)$ \\
\hline Maine & 455 & 161 (35) & Indiana & 609 & $62(10)$ \\
\hline Massachusetts & 1,630 & $415(25)$ & lowa & 35 & $4(\mathrm{II})$ \\
\hline New Hampshire & 323 & $138(43)$ & Kansas & 236 & $26(I I)$ \\
\hline New Jersey & 1,672 & $408(24)$ & Michigan & 722 & $165(23)$ \\
\hline New York & 3,345 & $747(22)$ & Minnesota & 291 & $50(17)$ \\
\hline Pennsylvania & 1,995 & $618(31)$ & Missouri & $\mathrm{I}, 520$ & $314(2 I)$ \\
\hline Rhode Island & 263 & $58(22)$ & Nebraska & 956 & $191(20)$ \\
\hline Vermont & 291 & $98(34)$ & North Dakota & 76 & $4(5)$ \\
\hline South & & & Ohio & 82 & $23(28)$ \\
\hline Alabama & 28 & $6(2 I)$ & South Dakota & 88 & $19(22)$ \\
\hline Arkansas & 135 & $14(10)$ & Wisconsin & 966 & $280(29)$ \\
\hline District of Columbia & 4 & $2(50)$ & West & & \\
\hline Delaware & 242 & $5 I(2 I)$ & Alaska & 245 & $3(1)$ \\
\hline Florida & 582 & $17(3)$ & Arizona & 277 & $34(12)$ \\
\hline Georgia & 892 & $102(1 \mathrm{I})$ & California & I,7I7 & $158(9)$ \\
\hline Kentucky & 125 & $24(19)$ & Colorado & 93 & $2(2)$ \\
\hline Louisiana & 194 & $27(14)$ & Hawaii & 5 & $2(40)$ \\
\hline Maryland & 1,250 & $97(8)$ & Idaho & 34 & $3(9)$ \\
\hline Mississippi & 112 & $17(15)$ & Montana & 148 & $49(33)$ \\
\hline North Carolina & 645 & $336(52)$ & Nevada & 582 & $25(4)$ \\
\hline Oklahoma & 60 & $7(12)$ & New Mexico & 27 & $2(7)$ \\
\hline South Carolina & 517 & $56(\mathrm{II})$ & Oregon & 785 & $135(17)$ \\
\hline Tennessee & 667 & $71(11)$ & Utah & 475 & $83(17)$ \\
\hline Texas & 1,636 & $257(16)$ & Washington & 44 & $8(18)$ \\
\hline Virginia & 2,013 & $336(17)$ & Wyoming & 87 & $9(10)$ \\
\hline West Virginia & 171 & $22(13)$ & & & \\
\hline
\end{tabular}

state divided by number of responding schools in that state), the values ranged from 0 to 0.29 (Table 2).

\section{School staff trained to recognize anaphylaxis}

Of the 6,019 schools that participated in the survey, 5,613 schools (93\%) provided information regarding staff members who were trained to recognize anaphylaxis. In response to the question, "Who in your school is trained to recognize the signs and symptoms of anaphylaxis?", the most common answer (reported by $36 \%$ of schools that provided data $[2,022 / 5,613])$ was that only the school nurse and select staff were trained (Figure 1A). Less than a third of schools $(1,730 / 5,613)$ trained all staff, and 29\% $(1,621 / 5,613)$ trained most staff in anaphylaxis recognition.

When analyzed by state, the percentage of schools that trained most or all staff in anaphylaxis recognition was highly variable (Table 2). All represented schools from Iowa, North Dakota, and Washington, as well as the District of Columbia, reported training most or all staff. However, most or all staff training rates as low as $13 \%$ were also observed.

\section{School staff who were permitted to administer epinephrine}

A total of 5,578 schools provided information on the types of staff who were permitted to administer epinephrine via an epinephrine auto-injector (EAI). The majority of schools $(54 \% ; 3,024 / 5,578)$ permitted the school nurse and select staff to administer epinephrine (Figure 1B). All or most staff were permitted to administer epinephrine in $38 \%$ of schools, and just $3 \%$ of schools limited EAI use to the school nurse or visiting state school nurse consultant (ie, a nurse who rotates among multiple schools to provide services as needed). Three percent of responding schools allowed both students and staff to administer epinephrine.

Regional and state data demonstrated a high level of diversity in the types of staff who were permitted to administer epinephrine (Table 2). In almost all cases, the proportion of schools that allowed most or all staff to administer epinephrine was lower than the proportion of schools that trained most or all staff to recognize anaphylaxis. There was no apparent correlation between most/all staff training levels and most/all staff administration levels. For example, the states listed above as 
Table 2 Percentage of anaphylactic events (relative to responding schools) and staff training by region and state

\begin{tabular}{|c|c|c|c|c|c|c|c|c|}
\hline State & $\begin{array}{l}\text { Anaphylactic } \\
\text { events per } \\
\text { school }^{\mathrm{a}}\end{array}$ & $\begin{array}{l}\text { Most/all staf } \\
\text { trained, \% }\end{array}$ & & $\begin{array}{l}\text { Most/all staff } \\
\text { permitted, \%c }\end{array}$ & State & $\begin{array}{l}\text { Anaphylactic } \\
\text { events per } \\
\text { school }^{\mathrm{a}}\end{array}$ & $\begin{array}{l}\text { Most/all staff } \\
\text { trained, \% }\end{array}$ & $\begin{array}{l}\text { Most/all staff } \\
\text { permitted, \% }\end{array}$ \\
\hline Northeast & & & & & Midwest & & & \\
\hline Connecticut & 0.27 & 60 & 25 & & Illinois & 0.16 & 80 & 57 \\
\hline Maine & 0.04 & 60 & 43 & & Indiana & 0.05 & 63 & 39 \\
\hline Massachusetts & 0.24 & 76 & 48 & & lowa & 0.25 & 100 & 25 \\
\hline New Hampshire & 0.13 & 63 & 35 & & Kansas & 0.15 & 52 & 36 \\
\hline New Jersey & 0.17 & 30 & 4 & & Michigan & 0.06 & 46 & 35 \\
\hline New York & 0.14 & 47 & 20 & & Minnesota & 0.10 & 67 & 37 \\
\hline Pennsylvania & 0.16 & 60 & 44 & & Missouri & 0.11 & 77 & 64 \\
\hline Rhode Island & 0.19 & 80 & 57 & & Nebraska & 0.03 & 59 & 44 \\
\hline Vermont & 0.06 & 68 & 41 & & North Dakota & 0 & 100 & 25 \\
\hline South & & & & & Ohio & 0.09 & 68 & 36 \\
\hline Alabama & 0 & 17 & 0 & & South Dakota & 0.16 & 58 & 47 \\
\hline Arkansas & 0.07 & 62 & 31 & & Wisconsin & 0.13 & 54 & 38 \\
\hline District of Columbia & 0 & 100 & 100 & & West & & & \\
\hline Delaware & 0.29 & 57 & 15 & & Alaska & 0 & 67 & 67 \\
\hline Florida & 0.12 & 82 & 71 & & Arizona & 0.15 & 64 & 50 \\
\hline Georgia & 0.26 & 66 & 50 & & California & 0.24 & 53 & 34 \\
\hline Kentucky & 0.17 & 74 & 43 & & Colorado & 0 & 50 & 0 \\
\hline Louisiana & 0.11 & 43 & 19 & & Hawaii & 0 & 50 & 0 \\
\hline Maryland & 0.20 & 84 & 52 & & Idaho & 0 & 67 & 67 \\
\hline Mississippi & 0.24 & 13 & 6 & & Montana & 0.08 & 72 & 70 \\
\hline North Carolina & 0.06 & 54 & 33 & & Nevada & 0.20 & 65 & 50 \\
\hline Oklahoma & 0.29 & 57 & 57 & & New Mexico & 0 & 50 & 50 \\
\hline South Carolina & 0.07 & 40 & 34 & & Oregon & 0.08 & 42 & 19 \\
\hline Tennessee & 0.17 & 66 & 59 & & Utah & 0.19 & 73 & 61 \\
\hline Texas & 0.17 & 75 & 44 & & Washington & 0.25 & 100 & 38 \\
\hline Virginia & 0.21 & 61 & 34 & & Wyoming & 0 & 83 & 67 \\
\hline West Virginia & 0 & 59 & 55 & & & & & \\
\hline
\end{tabular}

Notes: aThe number of anaphylactic events per school was calculated as the number of anaphylactic events in a given state divided by the number of responding schools in that state. bSchools training most or all staff to recognize signs of anaphylaxis. This proportion was calculated relative to the number of schools in the indicated state that responded to the survey question about staff training to recognize the symptoms of anaphylaxis, which may differ from the overall number of participating schools in that state. 'Schools permitting most or all staff to treat anaphylaxis with an epinephrine auto-injector. This proportion was calculated relative to the number of schools in the indicated state that responded to the survey question about staff permission to treat anaphylaxis with an epinephrine auto-injector, which may differ from the overall number of participating schools in that state.

having $100 \%$ training for recognition of signs and symptoms for most or all staff had comparatively low levels (25\%-38\%) of permission for EAI administration by most or all staff. However, in general, states with a high proportion of schools in which most or all school staff were permitted to administer epinephrine had a high proportion of schools that trained most or all staff on anaphylaxis recognition. For example, the five states listed as having $>65 \%$ permission for EAI administration by most or all staff(Alaska, Florida, Idaho, Montana, and Wyoming) also had relatively high rates of training for recognition of anaphylaxis signs and symptoms for most or all staff (67\%-83\%). (Note: the rate of permission was $100 \%$ for the District of Columbia, but there were only two schools in the District of Columbia that responded to the survey.)

\section{Discussion}

The results of this descriptive pilot study show that schools' preparedness for managing anaphylaxis varies substantially.
Training in the recognition of anaphylaxis predominantly included the school nurse and select staff, and regional/state proportions of schools in which most or all staff were trained ranged from $13 \%$ to $100 \%$. In general, fewer staff were permitted to administer epinephrine than were trained to recognize anaphylaxis signs and symptoms. In the majority of cases (54\%), only the school nurse and select staff members were allowed to administer epinephrine. On a regional/state basis, the proportion of schools in which most or all school staff were permitted to treat anaphylactic events with EAIs ranged from $0 \%$ to $100 \%$.

Few studies have evaluated school staff training in anaphylaxis recognition, anaphylaxis management, or both. When such studies have been conducted, they have typically involved a geographically limited sample. For example, a recent survey of food allergy management readiness included 78 schools from southeastern Wisconsin. Forty nine of the schools $(66 \%)$ reported that they provided staff training on anaphylaxis and epinephrine. ${ }^{13}$ 
A

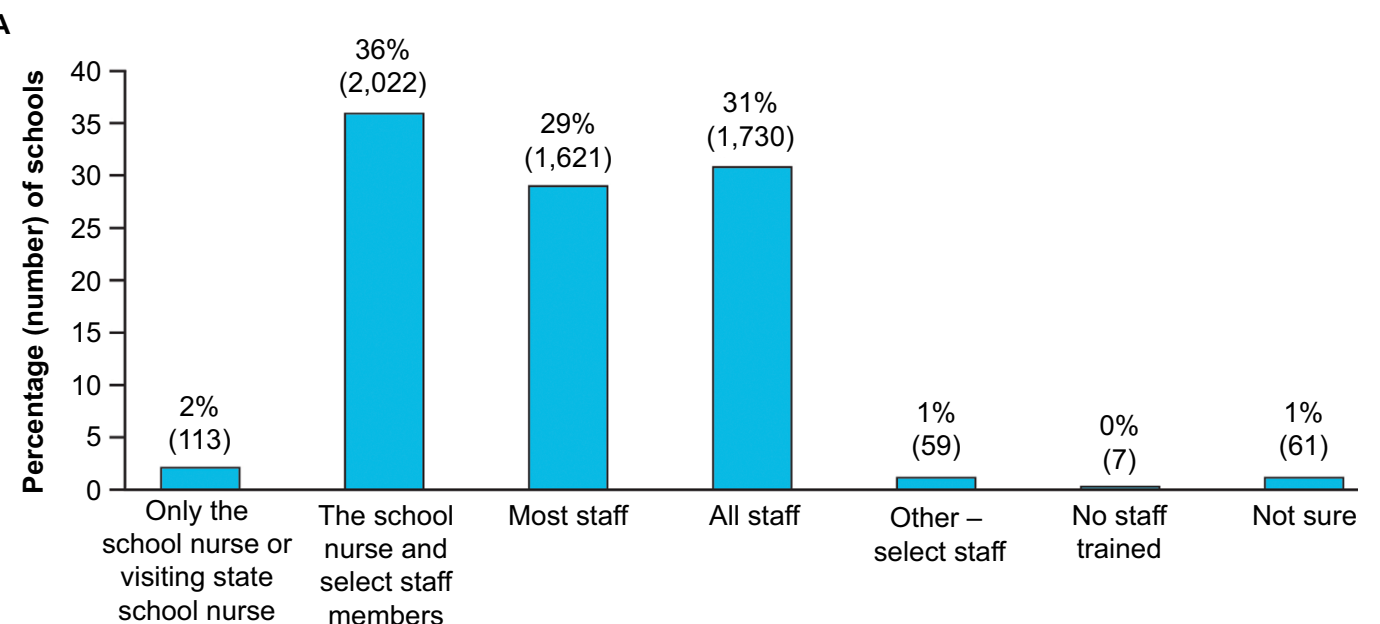
school nurse members consultant

Staff trained

B

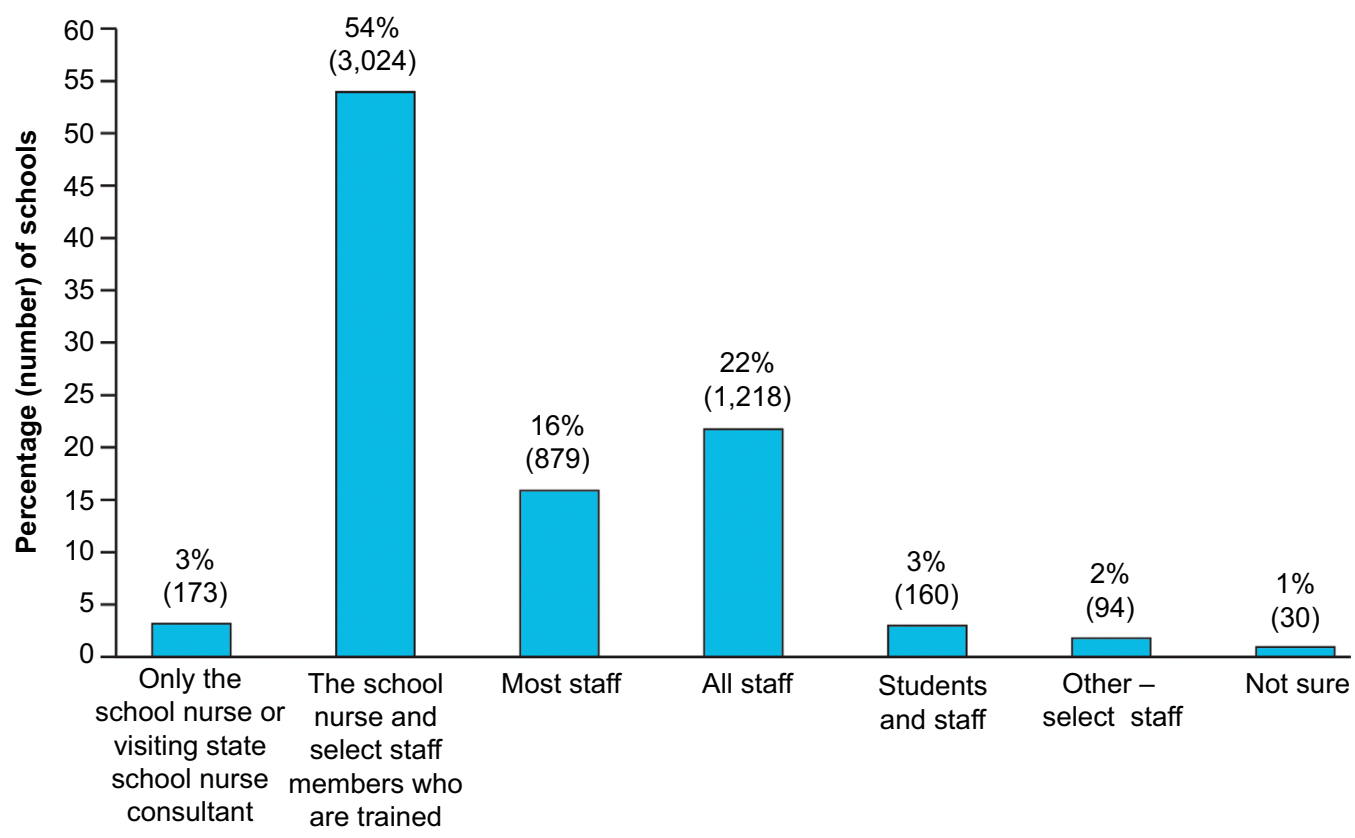

Staff allowed to administer

Figure I School staff training and permission.

Note: Types of school staff $(\mathbf{A})$ trained to recognize the signs and symptoms of anaphylaxis and $(\mathbf{B})$ permitted to administer epinephrine using an epinephrine auto-injector.

By expanding training and the ability to treat anaphylaxis, schools are better able to provide a timely response and, hence, increase the potential for a more favorable outcome. Evaluations of pediatric emergency department records have shown that less than half of children presenting with anaphylaxis received treatment with epinephrine in the prehospital setting. ${ }^{5,6}$ One of these studies reported that $12 \%$ of the analyzed anaphylactic reactions occurred at school. ${ }^{6}$ Of those, $69 \%$ of children were administered epinephrine by the school nurse. With the increasingly limited number of full-time school nurses ${ }^{6}$ and the potential for events to occur during field trips, before/after school hours, or during extracurricular activities, ${ }^{14}$ depending on a limited pool of trained responders may put children at risk.

Along with the need for adequate staff training, it is important for schools to stock epinephrine because of the risk of reactions in individuals without previously known life-threatening allergies ${ }^{3}$ and because children and adolescents with known risk factors often fail to carry an unexpired $\mathrm{EAI}^{15}$ or do not have ready access to an EAI. ${ }^{16}$ Additionally, the majority of individuals at high risk of anaphylaxis do not receive personal prescriptions for EAIs. ${ }^{17}$ In the EpiPen4Schools survey, 22\% of reported anaphylactic events occurred in individuals with no known allergies. ${ }^{12}$ The 
majority of anaphylactic events (75\%) reported were treated using EAIs; of these events, 49\% were treated with stock EpiPen Auto-Injectors from the EpiPen4Schools program. ${ }^{12}$ Most of the events that were not treated with an EAI were instead treated with antihistamines. ${ }^{12}$

Most states have legislation in place that allows schools to stock epinephrine. ${ }^{18}$ Nine states - California, Delaware, Maryland, Michigan, Nebraska, Nevada, New Jersey, North Carolina, and Virginia - have legislation that requires schools to stock epinephrine. ${ }^{18}$ Nonetheless, in a survey of school nurses from California, where stocking epinephrine and administration training for unlicensed assistive personnel are permitted, only $13 \%$ reported that their school had a stock epinephrine program in place. ${ }^{19}$ Moreover, despite the large presence of children with known food allergies, only $43 \%$ of schools from a Houston, Texas, school district reported having a stock EAI. ${ }^{20}$ Schools with lower socioeconomic status were less likely than schools with higher socioeconomic status to stock EAIs. Most states have laws regarding students carrying and self-administering prescribed epinephrine. ${ }^{21}$ While typically allowed by law, special approval is usually required. Since only $3 \%$ of responding schools said they allowed both students and staff to administer epinephrine, this suggests that, in practice, self-administration of EAIs by students may not be broadly permitted.

As a voluntary survey that was open to a subset of US schools (ie, those schools with a potentially higher allergy awareness information base as they were already participating in the EpiPen4Schools program), the interpretation of these results is subject to inherent limitations (eg, reporting bias, respondent recall, variance related to interpretation of meaning). In addition, survey results were not adjusted for potential confounding factors such as regional variations in the size of the student populations and types of schools. Future studies may benefit from deeper analyses of the details surrounding each event, including specifics of treatment administered, location of the event, and hospital transport and follow-up; demographic data such as race/ethnicity and sex may also be probed. Moreover, additional questions pertaining to the reasons for limited staff training or permission to treat, including regulations enacted by state or local governing bodies such as school boards, could provide greater insight into barriers that may prevent more extensive staff involvement in anaphylaxis management.

\section{Conclusion}

The risks and costs associated with anaphylaxis warrant that schools be prepared to act quickly both in the recognition of an anaphylactic event and in its treatment. Broader training of school staff, expanded staff involvement in treatment, and ready availability of medication are necessary to achieve this goal. The extent to which US schools have met these criteria is highly variable, both among schools and regions/states. To provide the best possible outcomes for children, barriers to their timely care within the school setting need to be identified and resolved.

\section{Acknowledgments}

This study was supported by Mylan Specialty L.P. Editorial assistance was provided under the direction of the authors by Crystal Murcia, PhD, Todd Parker, PhD, and Jennifer Rossi, MA, MedThink SciCom, and supported by Mylan Specialty L.P. BioRidge Pharma maintains the database of schools registered with the EpiPen4Schools program and provided logistical mailing services for survey invitation letters sent to identified contacts at participating schools. The authors would also like to acknowledge Margaret J Wooddell for her contributions to conception and critical feedback of early drafts.

\section{Disclosure}

Susan L Hogue, Diana Goss, Kelly Hollis, and Suyapa Silvia have no conflicts of interest in this work. Martha V White has served as a consultant for Mylan Specialty L.P. and Merck; has served as a board member for the Allergy and Asthma Network Mothers of Asthmatics; and has received grants, fees, or support from Mylan Specialty L.P., Merck, CSL Behring, AstraZeneca, Shire, Salix, Novartis, Teva, GlaxoSmithKline, Dyax, and Optinose.

\section{References}

1. Weiss C, Muñoz-Furlong A, Furlong TJ, Arbit J. Impact of food allergies on school nursing practice. J Sch Nurs. 2004;20(5):268-278.

2. Branum AM, Lukacs SL. Food allergy among children in the United States. Pediatrics. 2009;124(6):1549-1555.

3. McIntyre CL, Sheetz AH, Carroll CR, Young MC. Administration of epinephrine for life-threatening allergic reactions in school settings. Pediatrics. 2005;116(5):1134-1140.

4. Powers J, Bergren MD, Finnegan L. Comparison of school food allergy emergency plans to the Food Allergy and Anaphylaxis Network's standard plan. $J$ Sch Nurs. 2007;23(5):252-258.

5. Huang F, Chawla K, Järvinen KM, Nowak-Węgrzyn A. Anaphylaxis in a New York City pediatric emergency department: triggers, treatments, and outcomes. J Allergy Clin Immunol. 2012;129(1):162.e1-168.e3.

6. Tiyyagura GK, Arnold L, Cone DC, Langhan M. Pediatric anaphylaxis management in the prehospital setting. Prehosp Emerg Care. 2014;18(1):46-51.

7. Alqurashi W, Stiell I, Chan K, Neto G, Alsadoon A, Wells G. Epidemiology and clinical predictors of biphasic reactions in children with anaphylaxis. Ann Allergy Asthma Immunol. 2015;115(3):217-223.

8. Sasaki K, Sugiura S, Matsui T, et al. A workshop with practical training for anaphylaxis management improves the self-efficacy of school personnel. Allergol Int. 2015;64(2):156-160. 
9. Bock SA, Muñoz-Furlong A, Sampson HA. Further fatalities caused by anaphylactic reactions to food, 2001-2006. JAllergy Clin Immunol. 2007;119(4):1016-1018.

10. Patel DA, Holdford DA, Edwards E, Carroll NV. Estimating the economic burden of food-induced allergic reactions and anaphylaxis in the United States. J Allergy Clin Immunol. 2011;128(1):110-115.

11. Dunn JD, Sclar DA. Anaphylaxis: a payor's perspective on epinephrine autoinjectors. Am J Med. 2014;127(1 Suppl):S45-S50.

12. White MV, Hogue SL, Bennett ME, et al. EpiPen4Schools pilot survey: occurrence of anaphylaxis, triggers, and epinephrine administration in a U.S. school setting. Allergy Asthma Proc. 2015;36(4):306-312.

13. Eldredge C, Patterson L, White B, Schellhase K. Assessing the readiness of a school system to adopt food allergy management guidelines. WMJ. 2014;113(4):155-161.

14. Allen K, Henselman K, Laird B, Quiñones A, Reutzel T. Potential lifethreatening events in schools involving rescue inhalers, epinephrine autoinjectors, and glucagon delivery devices: reports from school nurses. J Sch Nurs. 2012;28(1):47-55.
15. Spina JL, McIntyre CL, Pulcini JA. An intervention to increase high school students' compliance with carrying auto-injectable epinephrine: a MASNRN study. J Sch Nurs. 2012;28(3):230-237.

16. DeMuth KA, Fitzpatrick AM. Epinephrine autoinjector availability among children with food allergy. Allergy Asthma Proc. 2011;32(4):295-300.

17. Sclar DA, Lieberman PL. Anaphylaxis: underdiagnosed, underreported, and undertreated. Am J Med. 2014;127(1 suppl):S1-S5.

18. Foodallergy.org [homepage on the Internet]. McLean, VA: Food Allergy Research \& Education; c2015 [updated October 30, 2015; cited July 17, 2015]. Available from: http:/www.foodallergy.org/advocacy/epinephrine/map. Accessed July 17, 2015.

19. Morris P, Baker D, Belot C, Edwards A. Preparedness for students and staff with anaphylaxis. J Sch Health. 2011;81(8):471-476.

20. Shah SS, Parker CL, O'Brian Smith E, Davis CM. Disparity in the availability of injectable epinephrine in a large, diverse US school district J Allergy Clin Immunol Pract. 2014;2(3):288.e1-293.e1.

21. Baulsir B, Inniss B. Summary Matrix of State Laws Addressing Epi-Pen Use in Schools. St Paul, MN: The Network for Public Health Law; 2015.
Journal of Asthma and Allergy

\section{Publish your work in this journal}

The Journal of Asthma and Allergy is an international, peer-reviewed open access journal publishing original research, reports, editorials and commentaries on the following topics: Asthma; Pulmonary physiology; Asthma related clinical health; Clinical immunology and the immunological basis of disease; Pharmacological interventions and

\section{Dovepress}

new therapies. This journal is included in PubMed. The manuscript management system is completely online and includes a very quick and fair peer-review system, which is all easy to use. Visit http://www. dovepress.com/testimonials.php to read real quotes from published authors. 